\title{
Evaluating the E-government Based on BSC
}

\author{
Jianjun Cheng ${ }^{1}$, Sencheng Cheng ${ }^{1}$, and Meiju Yang ${ }^{2}$ \\ 1 Management school, Wuhan University of Technology, 430070, Wuhan, \\ P.R. China \\ Chengjianjun007@153.com; chengsc@whut.edu.cn \\ 2 College of Politics and Public Management, Jiujiang University, 332005, \\ Jiujiang, P.R. China \\ meijuyang@sina.com.cn
}

\begin{abstract}
The rapid development of information and communication technologies has given rise to the emerging of the $\mathrm{e}$-government. Various approaches have been adopted to evaluate the e-government. This paper suggests the Balanced Scoreboard approach and attempts to devise a systematic evaluation framework.
\end{abstract}

\section{Introduction}

The rapid development of information and communication technologies has given rise to the emerging of the e -government. The United Nations (UN) and the American Society for Public Administration (ASPA) defined e-government as "utilizing the Internet for delivering government information and services to citizens" [1]. E-government is defined by the Organization for Economic Cooperation and Development [2] as the use of ICTs, and particularly the Internet, as a tool to achieve better government. At present e-government may refer to narrower or broader areas: in one, it is defined as online service delivery; and in the other, it entails the capacity to transform public administration using information and communication technologies (ICTs) to introduce the concept of e-governance.

The objectives of e-government are to: bring government closer to citizens by providing them with easier access to information through personal computers, telephones and other resources; modernize public services in which "joined-up government" institutions communicate and work more effectively and efficiently; increase and capture revenue more efficiently; increase mechanisms to create more accountability and transparency in the public sector. For these reasons, the governments all over the world are implementing their e-government projects and programs. 
The governments throughout the world have invested hugely in e-governments, so they are confronted with the problem of evaluating the performance. Currently, there are a variety of e-government performance evaluation standards, but none is from the Balanced Scoreboard (BSC) perspective. This paper attempts to use BSC approach to the e-government evaluation in an effort to establish effective operational standards. The rest of the paper are structured as following: Section 2 analyzes the need to evaluate the e-government; Section 3 is an overview of the existing approaches to evaluating the e-government; Section 4 proposes a performance standards based on $\mathrm{BSC}$, the final section concludes the paper.

\section{The need to evaluate the e-government}

\subsection{The new model of e-government determines the need for performance evaluation}

As a part of systematic evaluation, performance evaluation began in the 1930s. It is a managerial method which can assess quantitatively the input, short-term benefits and long-term effects. Since 1970 s, the new public administration reform has prevailed across the world, and various techniques have been developed to evaluate the government's performance. In the United States, Britain, and other Western countries, performance has become one of the core elements to be evaluated regarding the government's achievements. E-government as a revolutionary change means not only technical change but also change in governance and structure. It requires totally new operation processes and performance evaluation standards compared with the traditional government. The evaluation results should be used to guide the development of e-government in the right direction and to enhance its efficiency.

\subsection{Status quo of the e-government determines the need to implement a performance evaluation}

At present e-government's overall efficiency is not high. According to the United Nations World Public Sector Report 2003 [3] " E -government at the Crossroads", there are there types of e-government: wasteful ones, that is, resources have been input but the government operations have not been optimized; pointless ones, that is, the operations of the government have been optimized, but have not been conducive to the social development goals; the meaningful ones, that is the operations of the government have been optimized so that people can really participate in the political process and contribute to human development. Most e-governments across the world belong to the first and the second type. $60 \%$ to $80 \%$ of e-government projects in the developing countries fail. They can be classified as wasteful e-governments. Only 15 countries can receive public comments on policy issues via internet. Only 33 countries allow people to submit form and pay the fines online. 


\section{Existing approaches to e-government evaluation}

A large amount of research has already been carried out to evaluate the egovernment. An overview of approaches shows that they cover different areas and aspects of e-government. They include various indicators that can be categorized in the following groups:

- E-readiness

- Back-office

- Front-office: Supply and demand

- Effects and impacts.

\subsection{E-readiness}

The existence and maturity of the right environment for launching and using egovernment solutions in individual areas are two key elements in the successful development of e-government and, by measuring enabling factors for IT, indicate the readiness of individual players (government, citizens and businesses) to participate in the electronic world, i.e. e-readiness. On the government's side this is mainly an issue relating to strategies, policies and action plans for the introduction and development of e-government, IT use policies, the adoption and use of information infrastructure, IT training, awareness of the advantages and problems of egovernment and issues relating to financing, motivation and obstacles for the development of e-government. External (citizens and businesses) aspects include primarily ownership, interests and the level of use of information infrastructure, reasons for their under-use and opinions on the development of e-government in general. These indicators partially overlap with the evaluation of the information society as a whole.

\subsection{Front-office}

The front-office area is studied from two complementary points of view: supply and demand. Supply-side approaches entail evaluating online supply, and only in individual cases does it also involve supply via other channels of communication such as digital television, mobile technologies, call centers, dedicated kiosks and so on. These approaches generally investigate availability, level of development, quality and other characteristics of individual websites, and portals as well as particular eservices and information content.

On the other side demand-side approaches study the field from the point of view of the users (citizens and businesses). This kind of research primarily involves investigating actual use of websites, portals, e-services, information content and other elements of supply, the level of interest in use and reasons for not using services as well as evaluations of the quality of services as perceived by the users and evaluation of their perceptions, requirements and needs.

\subsection{Back-office}


The research that has dealt with evaluating the back-offices has assessed the adoption and use of different information systems including data sharing and exchanging technologies (databases, document management, process and workflow management, data sharing and exchange between organizations, etc)

\subsection{Effects and impacts}

Approaches to effects and impact evaluation include assessments of the impact of egovernment on economic, social and democratic processes, such as cost and benefit analyses, impact on organization, work methods, etc.

A detailed review of these approaches reveals that they are focused mostly on individual area or aspect of e-government, first of all on dealing with customers (front-office), evaluating the supply-side of e-government and something less demand-side, while largely neglecting the back-office and the impact and effects of e-government. This proves the opening supposition that current approaches do not support a comprehensive e-government assessment, but only partial evaluations that cannot give policy makers evaluation elements for their decisions, especially not in the direction of transformative government, characterized by integrated services development, where quality highly depends on back-office systems.

\section{The BSC-based approaches to e-government}

\subsection{Introduction to BSC}

The Balanced Scorecard is a multi-perspective approach aiming, on the one hand, at the "balance" of a strategy by considering various perspectives and on the other, on the operationalization of the corresponding strategic goals and their "translation" into a set of measurable targets [4]. Originally, the concept was developed for the business area and contained the financial, customer, business process and learning perspective. The perspectives are interrelated through cause and effect relationships showing the ability to realize the strategy and to monitor this relationship.

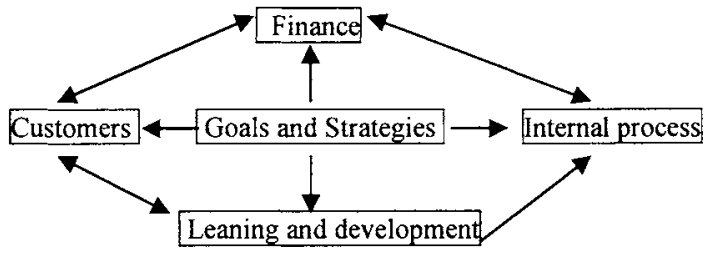

Fig. 1. BSC framework

\subsection{E-government evaluation Based on BSC}

\subsubsection{Financial indicators}

Governments belong to the non-profit sector, different from the general enterprises which set the economic benefits as the key of performance evaluation. The purposes 
of the government are to manage the society, and provide services for people. But this does not mean that the government will have no financial targets, the government's budget scale and operating costs have been important criterion for evaluating government performance. As a new government management model, the e-government's establishing and operating costs are important indicators that can not be ignored. Financial indicators generally include three aspects, namely, income, costs and asset utilization ratio. The income indicator, if included in performance evaluation standards, is inconsistent with the strategic goal of the e-governmentproviding services. But in a sense, the saving by the adoption of the e-government over the traditional one can be regarded as income and can be ranked as income indicator. "For cost indicators, they can be divided into two categories: one category is the cost of establishing the governmental websites; the other is the cost of running including software upgrading and hardware maintenance. For utilization ratio of assets, because the governments are different from enterprises, the indicator here is ignored. In addition, as a public service sector, their evaluation should include social benefit indicators. This can be translated into the total amount of money involved in the website transaction.

\subsubsection{Customer indicators}

Core indicators to measure customer dimensions include five aspects: market share, customers retention, Customer acquisition, customer satisfaction and customer profitability. In evaluating the value of the enterprises, the customer usually judge from product / service attributes, customer relationships, image and reputation. Based on customer dimensions in enterprises and in the light of the characteristics government, the authors summarized the e-government customer dimensions as follows.

Different government departments function differently, so the competitive indicators such as market share and customer retention do not have corresponding ones in the government performance evaluation. But the e-governments do have some competitive indicators. Competitions do exist between the traditional and information processing of governmental transactions, which can be represented by transaction information processing rate $(\mathrm{Re})$, that is, the rate of transactions(ne) handled by the government website in the total volume of departments transactions : $\mathrm{Re}=\mathrm{ne} / \mathrm{n}$. In addition, the number of people(hg) visiting the governmental websites in the total number of people(h) who have access to the internet can be another competitive indicator, that is $\mathrm{Rh}=\mathrm{hg} / \mathrm{h}$.

As for e-government product / service attributes, they can be measured by the service effect indicators. Using information technology to provide the public with information and quality services is one of the main tasks of the electronic government. Therefore the indicators concerning service effect include: the number of hits on the website, the downloaded number of document, the volume of transaction through website, the number of online windows opened and closed, the visiting number of databases and the visiting frequency of the information stored in the databases.

In customer relationship, the main concerns are the connection between the people and governmental websites. Apart from the number of e-mail people sent to the website, the interaction between the public and the websites, citizen's comments 
online and the response to the online survey should all be assessed. In addition, connection with other departments and agencies should also be measured.

The image and reputation of e-government can be reflected by the people's satisfaction in the services provided by e-governments. Satisfaction and credibility can be surveyed online or in other general ways. As the public expects rapid and quality services, any error can damage their satisfaction. The complaining rate( $\mathrm{Rt})$ on the website is also an effective measurement of e-government image and reputation. The complaining rate $(\mathrm{R} t)$ can be expressed by $(\mathrm{Qt}) / \mathrm{Q}$, here $\mathrm{Qt}$ refers to the quantity of complaints, and $Q$ represents the quantity of transactions.

\subsubsection{Internal process indicators}

Compared with the traditional performance evaluation approaches, the BSC is characterized by formulating goals and evaluation methods for the enterprise's internal operation. Unlike the enterprises, the internal processes of the e-government include: services provided, the maintenance, the security, collaboration with other departments and website and follow-up services. Indicators regarding internal process are based on the above.

Providing services is one of the main objectives of the e-government. Service attributes indicators are used to evaluating the services; one is the service content, the other the service quality, to be exact. Service content can be measured by the variety of services, the abundance of information provided and the craftsmanship of the web pages. Whether customized services are provided should also be considered.

The network serves as the platform the e-government. The maintenance and security are the prerequisites for improving the performance and can be summarized as technical attributes. For maintenance, it can be measured by the portal, bad(empty) link rate, the promptness of upgrading the software and etc. The security can be assessed by the resistance to virus and malicious invasion, and by the protection of privacy of those who log into the websites.

The e-government should be an island isolate from the outside. It should collaborate with other websites and department. Its influence can be measured by the links and the departments integrated together.

The sound follow-up services the enterprises can bring with them excellent images and quick development. In the same way, the e-governments need follow-up services for a better image and high public satisfaction. The follow-up services can measured by the time for the e-mails inquiry, the solution ratio to the complaints and etc.

\subsubsection{Learning and developing indicators}

The evaluation of the learning and developing capability lies in that it is a planning to implement finance, customer and internal operation procedures, in that it is a push to for the three to score. Evaluation in this aspect involves mainly human resource development and environmental building. The indicators include: employee quality, working environment, innovation and learning capability. 


\section{Conclusion}

E-government evaluation is important in that it provides direction for development, for decision making and for improvement. But current approaches do not support a comprehensive e-government assessment, but only partial evaluations that cannot give policy makers evaluation elements for their decisions. This paper suggests the $\mathrm{BSC}$ approach, it combines technology and service, and it is more comprehensive and operational. Experimental research is needed to test its effectiveness.

\section{References}

1 . United Nations/American Society for Public Administration (UN/ASPA). 2002.Benchmarking E-Government: A Global Perspective. New York: UN/ASPA.

2. Organization for Economic Co-operation and Development (OECD).. 2003. The EGovernment Imperative: Main Findings. Paris: OECD.

3. United Nations (UN). (2004). UN Global E-Government Survey 2003. New York: United Nations Online Network in Public Administration and Finance(UN/PAN).

4. Robert S. Kaplan; David P. Norton: The balanced scorecard - translating strategy into action, Harvard Business School Press, Boston, 1996. 